\title{
Optimalisasi Penghimpunan Dana Wakaf Melalui E-Payment
}

\author{
Angga Syahputra ${ }^{1 *}$, Khalish Khairina ${ }^{2)}$ \\ 1,2Fakultas Ekonomi dan Bisnis Islam, IAIN Lhokseumawe \\ *Email korespondensi: anggasyahputra@iainlhokseumawe.ac.id
}

\begin{abstract}
Waqf is a philanthropy with the highest position in Islam. Apart from being of worship value, waqf is also related to legal, social and economic aspects. The times demand waq not only in the form of immovable objects such as land and buildings, but also in the form of money. Cash waqf in its development can have a wider impact that can be felt by the community. To optimize the collection of waqf funds, the role of e-payment as a resulting technological innovation needs to be studied more deeply. This study uses a qualitative research type with a literature study model in answering these problems. Data is obtained from various reading sources such as books, previous studies, journals and trusted websites. This research shows that e-payment is proven to help optimize the collection of waqf funds. E-payment can facilitate wäqif in waqf both in terms of mobilization and the amount of funds to be donated. In addition, e-payments are proven to be safer, more convenient and efficient.
\end{abstract}

Keywords : waqf, cash waqf, e-payment

Saran sitasi: Syahputra, A., \& Khairina, K. (2021). Optimalisasi Penghimpunan Dana Wakaf Melalui E-Payment. Jurnal Ilmiah Ekonomi Islam, 7(01), 106-112. doi: http://dx.doi.org/10.29040/jiei.v7i1.1536

DOI: http://dx.doi.org/10.29040/jiei.v7i1.1536

\section{PENDAHULUAN}

Wakaf memiliki peran penting dalam mengentaskan kemiskinan dan masalah-masalah sosial yang ada dalam masyarakat. Bukti-bukti empiris menunjukkan banyaknya masyarakat yang hidup dalam garis kemiskinan salah satu penyebabnya adalah distribusi kekayaan yang tidak adil (Nawawi, 2011). Wakaf merupakan kegiatan sukarela dalam agama Islam. Wakaf juga merupakan salah satu instrument dalam Islam menuju kehidupan yang lebih sejahtera. Wakaf memiliki kelebihan dari amalan seperti zakat, infaq dan sedekah. Jika zakat, infaq dan sedekah setelah terdistribusikan akan habis wujud maupun manfaatnya, namun tidak begitu dengan wakaf (Hazami, 2016).

Ada sekitar 1,9 miliar Muslim di dunia. Indonesia sendiri memiliki jumlah Muslim terbesar di dunia dengan persentase $87.2 \%$ dari jumlah penduduknya, sehingga diperkirakan ada 229 juta umat Muslim di Indonesia (IBTimes.ID, 2020). Jumlah Muslim yang besar ini merupakan potensi wakaf yang sangat besar jika dapat dioptimalkan, namun sayangnya potensi ini belum dikelola dengan baik. Selama ini wakaf sering diarahkan hanya dalam bentuk benda tidak bergerak seperti tanah, bangunan dan sumur untuk diambil airnya (Lubis, 2020). Masyarakat pun memiliki stigma bahwa berwakaf harus dalam bentuk tanah, bangunan (Kementerian Keuangan, 2019) atau sejumlah dana dalam jumlah yang besar, sehingga membuat masyarakat enggan untuk berwakaf dan lebih memilih menyalurkannya dalam bentuk zakat, infaq atau sedekah.

Berwakaf dalam bentuk tanah, bangunan, atau benda tidak bergerak lainnya memiliki keterbatasan, yaitu manfaatnya hanya dapat dirasakan masyarakat sekitar tempat harta wakaf tersebut saja. Sementara masyarakat yang kurang mampu atau membutuhkan bantuan banyak tersebar di seluruh pelosok negeri. Untuk itu diperlukan sumber pendanaan baru yang tidak terikat dengan tempat dan waktu, sehingga manfaatnya dapat dirasakan kalangan yang lebih luas (Aziz, 2017).

Indonesia sendiri telah membolehkan wakaf uang dengan dikeluarkannya fatwa oleh Majelis Ulama Indonesia tentang Wakaf Uang pada 11 Mei 2002. Wakaf uang (waqf al-nuqud) dalam fatwa tersebut diartikan sebagai wakaf yang dilakukan seseorang, kelompok orang, lembaga atau badan hukum dalam 
bentuk uang tunai (Majelis Ulama Indonesia, 2002). Fatwa tersebut juga menegaskan bahwa dalam pengelolaannya, nilai pokok wakaf uang harus dijaga kelestariannya, tidak boleh dijual, dihibahkan dan/atau diwariskan.

Menggerakkan program wakaf melalui wakaf uang merupakan salah satu jalan yang memberikan kemudahan bagi masyarakat dalam menyalurkan niatnya untuk berwakaf. Optimalisasi wakaf dalam bentuk uang juga merupakan salah satu jalan terdistribusinya harta agar lebih merata. Wakaf uang sendiri, selain menjadi potensi namun turut menjadi tantangan dalam pengelolaannya, karena selama ini banyak masyarakat yang berwakaf uang namun tidak terdata baik dari jumlah yang diberikan maupun pada tempat mana wakaf tersebut disalurkan (Muhyidin, 2018).

Kementerian Agama saat ini telah menetapkan Lembaga Keuangan Syariah Penerima Wakaf Uang (LKS-PWU) sebanyak 22 lembaga per Agustus 2020 yang tertuang dalam Keputusan Menteri Agama (Susanto, 2020). Hastuti dalam penelitiannya menyimpulkan bahwa LKS-PWU memiliki peran yang penting dalam optimalisasi wakaf uang. LKSPWU terbukti memberikan kemudahan pada wāqif dalam menyalurkan wakaf uangnya (Hastuti, 2017). Sejalan dengan itu, Furqon (2011) juga dalam hasil penelitiannya menuliskan bahwa LKS-PWU berperan dalam menghimpun dana wakaf masyarakat dan menyalurkannya untuk kepentingan masyarakat banyak seperti rumah sakit dan pondok pesantren. Harrieti dan Mulyati (2017) dalam penelitiannya tentang peran bank syariah dalam pengelolaan wakaf uang juga menyimpulkan bahwa bank syariah memiliki andil yang sangat besar dalam mengelola dan mengoptimalkan dana wakaf yang ada pada masyarakat.

Dari LKS-PWU yang telah ditetapkan saat ini, rata-rata memiliki platform e-payment (aplikasi pembayaran elektronik) yang berfungsi menghimpun dana wakaf dan melaporkannya dalam sistem yang terhubung dengan Badan Wakaf Indonesia (BWI). Epayment ini diluncurkan untuk memudahkan waqif dalam berwakaf uang dan dianggap lebih transparan (Berakon, Irsad, Hanif, \& Fisa, 2017). E-Payment atau electronic payment dapat diartikan sebagai pembayaran yang dilakukan secara elektronik. Epayment dalam keseharian terbukti memberikan kemudahan, meningkatkan kenyamanan, cepat dan efesien (Trihasta, Deni, \& Fajaryanti, 2008). Oleh karena itu, penelitian ini ingin membahas sejauh mana peran e-payment yang dimiliki LKS-PWU maupun lembaga filantropi Islam lainnya dalam mengoptimalisasi penghimpunan wakaf di Indonesia.

\section{METODE PENELITIAN}

Penelitian ini menggunakan jenis penelitian kualitatif. Dimana dalam penelitian ini akan ditinjau bagaimana optimalisasi penghimpunan dana wakaf melalui e-payment. E-payment sendiri merupakan inovasi yang dihasilkan berkat kemajuan industri teknologi. Peneliti menggunakan metode studi literatur dalam menyelesaikan penelitian ini. Studi literatur dapat diartikan mengambil dan mengumpulkan data baik itu dari buku, jurnal, penelitian terdahulu maupun website terpercaya kemudian membacanya, mencatat dan diolah menjadi bahan penelitian.

\section{HASIL DAN PEMBAHASAN \\ 3.1. Wakaf dan Wakaf Uang}

Para ulama memiliki pandangan yang berbedabeda tentang defenisi dari wakaf. Faishal Haq berpendapat bahwa perbedaan definisi wakaf oleh para ulama madzhab dikarenakan wakaf mempunyai 25 arti lebih, meski yang lazim dipakai adalah arti menahan dan mencegah. Arti-arti yang banyak ini mempengaruhi para mujtahid dalam menetapkan definisi wakaf (Haq, 1993).

Wakaf berasal dari bahasa Arab, yaitu: waqafa, yaqifu, waqfan yang memiliki arti menahan, berhenti atau menetap (Ma'lūf, t.th). Secara umum, wakaf dapat diartikan sebagai kegiatan menahan harta yang dapat dimanfaatkan tanpa lenyap bendanya dengan cara tidak melakukan tindakan hukum terhadap benda tersebut, disalurkan pada sesuatu yang mubah (tidak haram) yang ada (al-Ramli, 1984). Said Sabiq berpendapat bahwa wakaf adalah menahan benda asal dan memanfaatkan buahnya (hasil) atau menahan harta dan menyalurkan manfaatnya di jalan Allah (Sābiq, 1971). Pengertian yang dipaparkan para ulama memiliki sebuah benang merah bahwa tujuan wakaf adalah sebagai sarana ibadah sosial yang diperintahkan agama. Setiap Muslim yang memiliki harta kekayaan dianjurkan untuk mewakafkan hartanya sesuai dengan syarat yang telah ditetapkan syariat (Hidayatullah, 2016).

Menurut Mundzir Qahaf, wakaf adalah kegiatan memberikan harta atau pokok benda yang produktif terlepas dari campur tangan pribadi, menyalurkan 


\section{Jurnal Ilmiah Ekonomi Islam, 7(01), 2021, 108}

hasil dan manfaatnya secara khusus sesuai dengan tujuan wakaf, baik untuk kepentingan perorangan, masyarakat, agama atau umum (Qahaf, 1995).

Indonesia sendiri dalam mendefenisikan wakaf, cenderung mengarah pada pandangan madzhab Imam Syafi'i. Definisi wakaf di Indonesia termaktub dalam peraturan Pemerintah nomor 28 tahun 1977 pasal 1 (1) yang berbunyi: "Wakaf adalah perbuatan hukum seseorang atau badan hukum yang memisahkan sebagian dari harta kekayaaannya yang berupa tanah milik dan melembagakannya untuk selama-lamanya untuk kepentingan peribadatan atau keperluan umum lainnya sesuai dengan ajaran agama Islam" (Ali, 1988).

Uang memiliki peranan yang penting dalam kegiatan transaksi ekonomi di berbagai belahan dunia, karena saat ini uang tidak hanya berfungi sebagai alat tukar, tetapi sudah dianggap sebagai benda meskipun terjadi perbedaan pendapat di antara ulama fikih, terkait fungsi uang sebagai komoditi yang dapat diperdagangkan. Ulama di Pakistan sudah membolehkan adanya wakaf uang dengan istilah cash wakaf, waqf al-nuqud yang diterjemahkan ke dalam bahasa Indonesia menjadi wakaf uang (Hidayatullah, 2016).

Uang juga merupakan modal utama dalam berbagai pembangunan dan perubahan perekonomian. Dewasa ini bahkan, nyaris tidak ada satu pun negara yang terlepas dari uang dalam membiayai program pembangunannya. Ironisnya, pembangunan di berbagai negara dengan mayoritas Muslim masih didominasi dengan hutang. Padahal, Islam tidak pernah mengajarkan untuk berhutang apalagi menumpuk-numpuk hutang yang akan membebani masyarakat dan generasi setelahnya. Untuk itu, wakaf uang merupakan salah satu alternatif yang dapat difungsikan dalam meminimalisir hal tersebut. Selain dapat membantu pemerintah, berwakaf dapat menjadi solusi dalam mensejahterakan umat (Kholid, 2011).

Imam al-Zuhri (w.124 H) berpendapat bahwa mewakafkan dinar hukumnya boleh, dengan cara menjadikan dinar tersebut sebagai modal usaha kemudian keuntungannya disalurkan kepada mauquf 'alaih (Muhammad, 1997). Pandangan ini juga sejalan dengan pandangan sebagian ulama mazhab Imam Syafi'i bahwa wakaf dinar dan dirham diperbolehkan (al-Mawardi, 1994). Syeikh Jad al-Haqq (mantan Shaikh Al-Azhar) mengatakan, bahwa menurut Muhammad dari mazhab Hanafi, boleh mewakafkan dirham dan dinar. Para Syeikh di Al-Azhar juga sepakat tentang hal ini, yaitu boleh wakaf uang dirham dan dinar. Dalam kitab al is 'af dikatakan, bahwa pendapat Muhammad itulah yang sahih (benar) dan pendapatnyalah yang difatwakan (Haqq, 1994).

Istilah wakaf tunai dipopulerkan oleh A. Mannan, seorang pemikir ekonomi Islam dari Bangladesh dengan istilah cash waqf (Masyitah, 2002). A. Mannan mendirikan sebuah badan bernama Social Investment Bank Limited (SIBL) di Bangladesh. Lembaga yang didirikan oleh A. Mannan ini memperkenalkan produk sertifikat wakaf tunai (cash waqf certificate) yang pertama kali dalam sejarah perbankan. SIBL menggalang dana dari orang kaya untuk dikelola dan keuntungan pengelolaan disalurkan kepada rakyat miskin.

Menurut Syafii Antonio, dalam catatan sejarah Islam, cash waqf ternyata sudah dipraktekkan sejak awal abad kedua hijriah (Antonio, 2003). Antonio berargumentasi dengan sebuah riwayat dari Imam Bukhari, bahwa Imam Azzuhri (w. 124 H) salah seorang ulama terkemuka dan peletak dasar tadwin al hadits memfatwakan, dianjurkan wakaf dinar dan dirham untuk pembangunan sarana dakwah, sosial dan pendidikan umat Islam. Adapun caranya adalah dengan menjadikan uang tersebut sebagai modal usaha kemudian menyalurkan keuntungannya sebagai wakaf.

Saat ini, sejumlah kiai (pimpinan pondok pesantren) telah mempraktekkan gagasan ini dengan cara melelang tanah yang akan dibeli untuk pengembangan pondok pesantren yang diasuhnya dengan menghargakan tanah per meternya sehingga wāqif dapat membayar tanah tersebut sesuai dengan kemampuannya melalui nomor rekening bank yang sudah disiapkan oleh panitia. Meskipun akad yang dilakukan adalah wakaf tanah, dalam prakteknya yang diberikan oleh wāqif adalah uang (Mubarok, 2008).

Ketentuan tentang pelaksanaan wakaf uang di Indonesia diatur dalam Undang-Undang Nomor 41 Tahun 2004 Tentang Wakaf yaitu 1). Wāqif dibolehkan mewakafkan uang melalui Lembaga Keuangan Syariah yang ditunjuk oleh Menteri; 2). Wakaf yang dilaksanakan oleh wāqif dengan pernyataan kehendak wāqif yang dilakukan secara tertulis; 3). Wakaf diterbitkan dalam bentuk sertifikat wakaf uang; dan 4). Sertifikat wakaf uang diterbitkan dan disampaikan oleh Lembaga Keuangan Syariah kepada wāqif kemudian nazir mendaftarkan harta benda wakaf berupa uang kepada menteri selambat- 
lambatnya 7 hari kerja sejak diterbitkannya sertifikat wakaf uang.

Selain undang-undang tersebut, pelaksanaan wakaf uang juga diatur dalam Peraturan Pemerintah Nomor 42 Tahun 2006 Tentang Pelaksanaan Wakaf disebutkan yaitu: 1). Jenis harta yang diserahkan wāqif dalam wakaf uang adalah uang dalam valuta rupiah. Maka, uang yang akan diwakafkan harus dikonversikan terlebih dahulu ke dalam rupiah jika masih dalam valuta asing; dan 2). Wakaf uang dilakukan melalui Lembaga Keuangan Syariah yang ditunjuk oleh Menteri Agama sebagai LKS-Penerima Wakaf Uang (LKS-PWU).

Berwakaf dengan uang memiliki banyak kelebihan diantaranya lebih fleksibel, tidak mengenal wilayah pendistribusian, lebih mudah dihimpun, dan dapat secepatnya dimanfaatkan untuk kesejahteraan masyarakat (Aziz, 2017). Berwakaf dengan uang juga dinilai lebih produktif, karena selama ini berwakaf dengan tanah misalnya, banyak menimbulkan permasalahan, seperti keterbatasan lahan, lahan yang tidak subur, sehingga hal ini jauh dari tujuan wakaf yang sebenarnya. Berwakaf juga memiliki keuntungan dari segi amal ibadah, karena wakaf mengandung unsur muabbad (kontinuitas) yang memuculkan pahala terus-menerus meski wāqif telah meninggal dunia (Sabiq, 1992).

\subsection{Peran E-Payment dalam Menghimpun Wakaf Uang}

Era digitalisasi 4.0 ditandai dengan maraknya penggunaan teknologi dengan mengurangi peran manusia dalam pengerjaannya namun terbukti lebih efektif dan efesien dalam mencapai tujuan organisasi. Penghimpunan dana wakaf melalui e-payment merupakan bagian fundraising menggunakan teknologi guna memanjakan wāqif. Fundraising adalah istilah lain dalam penghimpunan dana wakaf dimana kegiatan ini merupakan proses mempengaruhi calon wāqif agar mau berwakaf (Badan Wakaf Indonesia, 2009).

Per 31 Agustus 2020, ada 22 LKS-PWU yang ditetapkan melalui Keputusan Menteri Agama, antara lain: Bank Muamalat, BNI Syariah, Bank Syariah Mandiri, Bank Mega Syariah, Bank DKI Syariah, BTN Syariah, BPD Yogyakarta Syariah, Bank Syariah Bukopin, BPD Jawa Tengah Syariah, BPD Kalimantan Barat Syariah, BPD Kepri Riau Syariah, BPD Jawa Timur Syariah, Bank Sumut Syariah, CIMB Niaga Syariah, Bank Panin Dubai Syariah, Bank Sumsel-Babel Syariah, BRI Syariah, BJB
Syariah, Bank Kaltim Kaltara Unit Usaha Syariah, BPRS Harta Insan Karimah, BPD Syariah Kalimantan Selatan, dan Bank Danamon (Unit Usaha Syariah) (Susanto, 2020).

Kemunculan LKS-PWU khususnya bank-bank syariah dalam menghimpun dana wakaf merupakan terobosan baru yang membawa perubahan besar dalam penghimpunan dana wakaf. Bank-bank syariah yang terdaftar dalam LKS-PWU umumnya saat ini menggunakan teknologi komputerisasi seperti $e$ payment dalam berwakaf uang, sehingga memudahkan wāqif. Calon wāqif tidak harus datang ke kantor fisik LKS-PWU, cukup dengan membuka smart phone maka dapat berwakaf uang dan terintegrasi dengan sistem yang ada pada BWI (Bimo \& Epita, 2018). Pada tahun 2019 sendiri pengguna ponsel pintar di Indonesia diprediksi sebanyak $63.3 \%$ dari jumlah penduduk Indonesia, artinya sekitar 170.6 juta masyarakat Indonesia saat ini memiliki smart phone (Jamilah, 2020).

Beberapa LKS-PWU memiliki platform $e$ payment dalam menghimpun dana wakaf. BTN Syariah memiliki aplikasi Mobile Wakaf Uang NU BTN Syariah. Aplikasi ini dalam penelitian Bimo dan Epita (2018) terbukti memudahkan calon wāqif dalam berwakaf. Aplikasi ini juga menyediakan Sertifikat Wakaf sebagai bukti bahwa wāqif telah berwakaf (BTN Syariah, 2020). BNI Syariah sendiri memiliki aplikasi e-payment Wakaf Hasanah yang sejauh ini berhasil menghimpun dana wakaf 8.25 miliar dari 7.198 wakif (Republika, 2020). Aplikasi Wakaf Hasanah ini menyediakan wakaf dengan nominal minimal Rp. 50.000 dan wāqif dapat memilih langsung kemana dananya akan diwakafkan (BNI Syariah, 2020).

Bank CIMB Niaga Syariah tidak mau ketinggalan dalam mengoptimalkan penghimpunan wakaf. Melalui aplikasi e-Salaam nasabah dapat berwakaf melalui smartphone. Aplikasi ini juga menyediakan pilihan kepada wāqif untuk menyalurkan dana wakafnya sesuai yang dikehendaki. Aplikasi e-Salaam bahkan menyediakan wakaf uang dengan nominal mulai dari Rp. 10.000 (CIMB Niaga Syariah, 2020). Bank Mandiri Syariah juga memiliki sistem e-payment wakaf melalui platform digital yang diberi nama Jadibekah.id. Aplikasi ini memudahkan wāqif dalam menyalurkan wakafnya dan dapat menentukan sendiri kemana dana wakaf yang akan diberikan, dengan minimal nominal berwakaf $\mathrm{Rp}$. 10.000 (Bank Mandiri Syariah, 2020). Furqon dalam 
penelitiannya tentang LKS-PWU pada Bank Mandiri Syariah menyimpulkan bahwa Bank Mandiri Syariah turut serta membantu mengoptimalkan penghimpunan wakaf dengan sumber daya yang ada (Furqon, Praktik Wakaf Uang di Bank Syariah Mandiri, 2012). Lain halnya dengan BRI Syariah, melalui aplikasi BRISOnline, calon wāqif dapat langsung terhubung dengan nazir wakaf yang pilihannya terdapat pada menu aplikasi untuk memudahkan penyaluran wakaf. Bahkan dengan Rp. 1.000 sudah dapat berwakaf melalui BRISOnline.

Optimalisasi penghimpunan dana wakaf melalui bank syariah yang telah ditetapkan pemerintah merupakan solusi terbaik. Hal ini dikarenakan bank syariah sebagai LKS-PWU memiliki akuntabilitas, profesionalisme, serta memiliki IT network (Wulandari, Effendi, \& Saptono, 2019). Selama ini diketahui bahwa penghimpunan dana wakaf kurang efektif dikarenakan sedikit dana wakaf yang dikelola profesional dan produktif (Berakon, Irsad, Hanif, \& Yasinta, 2017).

Selain yang terdaftar dalam LKS-PWU, beberapa lembaga filantropi Islam juga telah menggunakan platform e-payment untuk menjaring wāqif. Dengan nominal Rp. 10.000 sudah dapat berwakaf dan dapat memilih juga kemana wakaf tersebut untuk disalurkan (Dompet Dhuafa, 2020). Bahkan e-payment yang digunakan sudah bekerjasama dengan aplikasi OVO dan LinkAja. Data 2018, Dompet Dhuafa mampu mengumpulkan 2-3 miliar per bulan dengan kemudahan e-payment ini. Pada 2018 Dompet Dhuafa dapat menghimpun dana wakaf sebesar 35 miliar (Denura, 2019). Lembaga lain seperti Rumah Zakat juga menyediakan layanan yang sama, bahkan pada lama websitenya menu pilihan tujuan wakaf langsung dapat dipilih calon wāqif dengan minimal wakaf $\mathrm{Rp}$. 10.000 (Rumah Zakat, 2020).

Inovasi yang dihadirkan LKS-PWU maupun lembaga filantropi Islam dalam mengoptimalkan penghimpunan dana wakaf diharapkan mampu mengejar potensi wakaf uang yang ada. Dalam paparannya, Badan Wakaf Indonesia menuturkan ada potensi wakaf 180 triliun setiap tahunnya. Sementara berdasarkan data Kementerian Agama (2018), realisasi wakaf uang yang tercatat sejak tahun 2011 hingga 2018, rata-rata hanya Rp 31,9 miliar per tahunnya. Hal ini menunjukkan bahwa wakaf uang masih memiliki potensi yang sangat besar untuk dikembangkan (Kementerian Keuangan, 2019).
Ditengah inovasi dan kemudahan layanan dalam optimalisasi penghimpunan wakaf, masih banyak pekerjaan rumah yang harus dilakukan pemerintah, BWI, LSK-PWU maupun lembaga filantropi Islam untuk memaksimalkan fungsi e-payment dalam menghimpun dana wakaf. Sebagaimana kajian Kementerian Keuangan dan Badan Wakaf Indonesia tantangan-tantangan yang harus diselesaikan tersebut adalah: minimnya sosialisasi dan edukasi, tata kelola kelembagaan yang masih dibawah standar, terbatasnya fundraiser wakaf, serta kurangnya promosi program/kegiatan. Faktor fundamental sangat perlu diperbaiki agar dasar pengembangan lebih kuat seperti isu literasi, penguatan inklusi, dan peningkatan tata kelola wakaf uang sebelum wakaf uang nantinya dapat dimanfaatkan sebagai instrumen pendalaman pasar keuangan. Pekerjaan rumah yang terpenting dari hasil survei bahwa literasi maupun tingkat inklusivitas masyarakat masih rendah. Artinya sebagus apapun program yang ditawarkan jika sosialisasi dan penguatan penyelesaian permasalahan terkait literasi masyarakat belum ditingkatkan maka akan menjadi sulit untuk memperkenalkan dan mengakselerasi penghimpunan wakaf uang (Kementerian Keuangan, 2019).

\section{KESIMPULAN}

Penelitian ini menyimpulkan bahwa e-payment terbukti dapat membantu optimalisasi penghimpunan dana wakaf. E-payment yang dikelola oleh LKS-PWU maupun lembaga filantropi Islam mampu memudahkan calon wāqif untuk berwakaf tanpa harus datang ke kantor fisik lembaga, transaksi lebih aman, nyaman, kapanpun dan dimanapun serta tidak memberatkan calon wäqif. Dengan nominal Rp. 10.000 bahkan Rp. 1.000 calon wāqif sudah bisa berwakaf, tanpa harus menunggu dana yang dimiliki terkumpul lebih besar. Platform e-payment juga membantu transparansi data pengumpulan dan penyaluran dana wakaf serta terhubung dengan sistem Badan Wakaf Indonesia, sehingga capaian-capaian wakaf dapat diukur dan terkontrol jauh lebih baik.

\section{REFERENSI}

Ali, D. (1988). Sistem Ekonomi Islam: Zakat dan Wakaf. Jakarta: UI Press.

al-Mawardi. (1994). al-Hawi al-Kabir. Beirut: Dar alFikr.

al-Ramli. (1984). Nihayah al-Muhtaj ila Syarh alMinhaj (Vol. 5). Beirut: Dar al-Fikr. 


\section{Jurnal Ilmiah Ekonomi Islam, 7(01), 2021, 111}

Antonio, S. (2003, Maret 6). Wakaf Tunai dan Pendidikan Islam. Dipetik November 28, 2020, dari www.tazkiaonline.com

Aziz, M. W. (2017). Wakaf Tunai dalam Perspektif Hukum Islam. International Journal Ihya' 'Ulum Al-Din, $\quad 19(1), \quad$ 1-24, $\quad$ DOI: 10.21580/ihya.18.1.1740.

Badan Wakaf Indonesia. (2009, Januari 6). Manajemen Fundraising dalam Penghimpunan Dana Wakaf. Dipetik November 28, 2020, dari https://www.bwi.go.id/297/2009/01/06/manajem en-fundraising-dalam-penghimpunan-danawakaf/

Bank Mandiri Syariah. (2020). Wakaf. Dipetik November 28, 2020, dari https://www.jadiberkah.id/wakaf

Berakon, I., Irsad, A. M., Hanif, N. N., \& Fisa, H. (2017). E-Payment Inovasi Layanan Penghimpunan dan Redistribusi Wakaf Uang Berbasis Online dalam Percepatan Pembangunan Ekonomi Indonesia. Jurnal Al-Qardh, 5(1), 2641, DOI: 10.23971/jaq.v2i1.824.

Bimo, W. A., \& Epita, N. (2018). Sistem Informasi Wakaf Uang Melalui Mobile Payment Apps Tabungan BTN Batara IB Akad 'Wadiah' Pada PT. Bank Tabungan Negara Syariah (Persero) Tbk. Cabang bogor. Moneter: Jurnal Keuangan \& Perbankan, 6(1), 30-36, http://ejournal.uikabogor.ac.id/index.php/MONETER/index.

BNI Syariah. (2020). Donasi Wakaf. Dipetik November 28, 2020, dari https://wakafhasanah.bnisyariah.co.id/donatestep-1/73

BTN Syariah. (2020). Mobile Wakaf NU BTN Syariah. Dipetik November 28, 2020, dari https://www.btn.co.id/id/Syariah-Home/SyariahData-Sources/Product-Links-Syariah/ProdukBTN-Syariah/e-channel/E-Banking/MobileWakaf-NU-BTN-Syariah

CIMB Niaga Syariah. (2020). Baitul Wakaf e-Salaam. Dipetik November 28, 2020, dari https://esalaam.co.id/wakaf/7n84SL4k

Denura, F. (2019, Oktober 17). Pemberian Wakaf Bisa Dilakukan Lewat Platform Digital E-Payment. Dipetik November 29, 2020, dari https://www.arahkita.com/news/read/15184/pem berian_wakaf_bisa_dilakukan_lewat_platform_ digital_e_payment

Dompet Dhuafa. (2020). Dipetik November 29, 2020, dari https://donasi.dompetdhuafa.org/
Furqon, A. (2011). Analisis Praktek Perwakafan Uang Pada Lembaga Keuangan Syariah. Walisongo, 19(1), 157-178, DOI : 10.21580/ws.19.1.216.

Furqon, A. (2012). Praktik Wakaf Uang di Bank Syariah Mandiri. Al-Manahij: Jurnal Kajian Hukum Islam, 6(1), 113-128. https://doi.org/https://doi.org/10.24090/mnh.v6i 1.592 .

Haq, F. (1993). Hukum wakaf dan perwakafan di Indonesia. Pasuruan: PT Garoeda Buana Indah, 1993.

Haqq, J. a. (1994). Buhuth wa Fatawa Islamiyyah fi Qadaya al-Mu'asirah (1 ed.). Kairo: Al-Azhar al Sharif.

Harrieti, N., \& Mulyati, E. (2017). Peranan Perbankan Syariah dalam Pengelolaan Wakaf Uang di Indonesia. Al-Risalah: Forum Kajian Hukum dan Sosial Kemasyarakatan, 17(2), 137-146, DOI: 10.30631/al-risalah.v17i02.60.

Hastuti, Q. (2017). Peran Lembaga Keuangan Syariah Penerima Wakaf Uang (LKS-PWU) Bagi Optimalisasi Wakaf Uang. ZISWAF: Jurnal Zakat dan Wakaf, 4(1), 41-54, DOI: http://dx.doi.org/10.21043/ziswaf.v4i1.3030.

Hazami, B. (2016). Peran dan Aplikasi Wakaf Dalam Mewujudkan Kesejahteraan Umat Di Indonesia. Analisis, Volume Nomor 1, Juni 2016, XVI(1), 173-204, https://doi.org/10.24042/ajsk.v16i1.742.

Hidayatullah, S. (2016). Wakaf Uang Dalam Perspektif Hukum Islam dan Hukum Positif di Indonesia. SALAM; Jurnal Sosial \& Budaya Syar $-i \quad 3(1), \quad 1-20, \quad$ DOI: 10.15408/sjsbs.v3i1.3306.

IBTimes.ID. (2020, April 8). Data Populasi Penduduk Muslim 2020: Indonesia Terbesar di Dunia. Dipetik November 27, 2020, dari https://ibtimes.id/data-populasi-pendudukmuslim-2020-indonesia-terbesar-di-dunia/

Jamilah, A. (2020, Oktober 6). Pengguna Ponsel di Indonesia Bakal Mencapai 89 Persen Populasi pada 2025. Dipetik November 28, 2020, dari https://www.goodnewsfromindonesia.id/2020/1 0/06/pengguna-smartphone-di-indonesiadiperkirakan-mencapai-89-populasi-pada-2025

Kementerian Keuangan. (2019). Ringkasan Eksekutif: Strategi Pengembangan Wakaf Uang dalam Rangka Pendalaman Pasar Keuangan Syariah. Jakarta: Kemenkeu RI. 


\section{Jurnal Ilmiah Ekonomi Islam, 7(01), 2021, 112}

Kholid, H. (2011, Agustus 16). Wakaf Uang Perspektif Hukum dan Ekonomi Islam. Dipetik November 28, 2020, dari Badan Wakaf Indonesia: https://www.bwi.go.id/624/2011/08/16/wakafuang-perspektif-hukum-dan-ekonomi-islam/

Lubis, H. (2020). Potensi dan Strategi Pengembangan Wakaf Uang di Indonesia. IBF: Islamic Business and Finance, 1(1), 43-59.

Majelis Ulama Indonesia. (2002, Mei 11). Fatwa Wakaf Uang. Dipetik November 26, 2020, dari http://mui.or.id/wpcontent/uploads/files/fatwa/29.-Wakaf-Uang.pdf Ma'lūf, L. (t.th). Al-Mujid fi al- Lughah wa al-A'l à $m$. Beirut: Dar al- Mashriq.

Masyitah, D. (2002). Wakaf Tunai. Bandung: Harian Pikiran Rakyat.

Mubarok, J. (2008). Wakaf Produktif(I ed.). Bandung: Refika Offset.

Muhammad, A. S. (1997). Risalah fi Jawazi WaqfalNuqud. Beirut: Dar Ibn Hazm.

Muhyidin. (2018, Januari 26). Ini Enam Tantangan Perwakafan di Indonesia. Dipetik November 27, 2020, dari https://republika.co.id/berita/duniaislam/wakaf/18/01/26/p34v39396-ini-enamtantangan-perwakafan-diindonesia\#: :text=Tantangan $\% 201$ lainnya $\% 2 \mathrm{C} \%$ 20tambah\%20dia\%2C\%20yaitu,profesional $\% 2 \mathrm{C}$ $\% 20$ belum\%20tersedianya\%20data\%20base

Nawawi, Z. M. (2011). Kecenderungan Masyarakat Untuk Berwakaf Tunai (Studi Kasus Mahasiswa Fakultas Syari'ah IAIN Sumatera Utara). Media Syariah, $\quad$ XIII(2), 213-226, DOI: http://dx.doi.org/10.22373/jms.v13i2.1789.
Qahaf, M. (1995). Sanadât Al-Ijârah, Al-Ma'had AlIslâmy li Al-Buhûts wa At-Tadrîb. Kairo: Dar asSalam.

Republika. (2020, November 8). Dipetik November 28, 2020, dari https://republika.co.id/berita/qjgd0r383/platform -digital-bni-syariah-himpun-wakaf-rp-825miliar

Rumah Zakat. (2020). Wakaf. Dipetik November 29, 2020, dari https://www.rumahzakat.org/donasi/\#wakafproduktif

Sābiq, A. S. (1971). Fiqh al- Sunnah (Vol. III). Beirut: Dar al- Kitab al- 'Arabi.

Sabiq, S. (1992). Fiqhussunnah. Beirut: Darul Fikr.

Susanto, V. Y. (2020, September 5). Mau mewakafkan uang? Ini daftar 22 lembaga keuangan syariah penerima wakaf uang. Dipetik November 27, 2020 , dari https://nasional.kontan.co.id/news/maumewakafkan-uang-ini-daftar-22-lembagakeuangan-syariah-penerima-wakaf-uang

Trihasta, Deni, \& Fajaryanti, J. (2008). E-Payment Sistem. Seminar Ilmiah Nasional Komputer dan Sistem Intelijen (hal. 168, ISSN: 1411-6286). KOMMIT.

Wulandari, S., Effendi, J., \& Saptono, I. T. (2019). Pemilihan Nazhir Dalam Optimalisasi Pengelolaan Wakaf Uang. Jurnal Aplikasi Bisnis Dan Manajemen (JABM), 5(2), 295. https://doi.org/10.17358/jabm.5.2.295. 